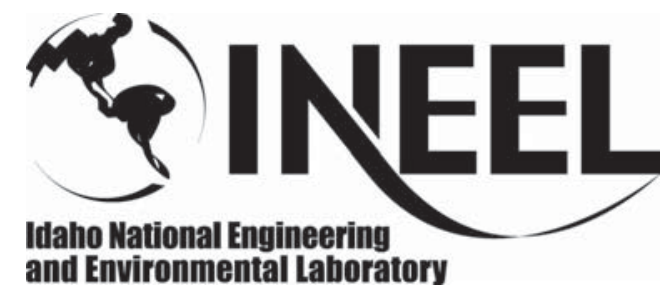

Itaho National Engineering

and Environmental Laboratory

\title{
Biomechanics of Wheat/Barley Straw and Corn Stover
}

\author{
Christopher T. Wright \\ Peter A. Pryfogle \\ Nathan A. Stevens \\ Eric D. Steffler \\ J. Richard Hess \\ Thomas H. Ulrich
}

March 2005

\section{6th Symposium on Biotechnology for Fuels and Chemicals}

This is a preprint of a paper intended for publication in a journal or proceedings. Since changes may be made before publication, this preprint should not be cited or reproduced without permission of the author.

This document was prepared as an account of work sponsored by an agency of the United States Government. Neither the United States Government nor any agency thereof, or any of their employees, makes any warranty, expressed or implied, or assumes any legal liability or responsibility for any third party's use, or the results of such use, of any information, apparatus, product or process disclosed in this report, or represents that its use by such third party would not infringe privately owned rights. The views expressed in this paper are not necessarily those of the U.S. Government or the sponsoring agency. 


\title{
Biomechanics of Wheat/Barley Straw and Corn Stover
}

\author{
Christopher T. Wright ${ }^{*}$, Peter A. Pryfogle, Nathan A. Stevens, \\ Eric D. Steffler, J. Richard Hess, and Thomas H. Ulrich \\ Idaho National Engineering and Environmental Laboratory \\ P.O. Box 1625, Idaho Falls, ID 83415-2210, E-mail: wrigct@inel.gov
}

\section{Summary}

The lack of understanding of the mechanical characteristics of cellulosic feedstocks is a limiting factor in economically collecting and processing crop residues, primarily wheat and barley stems and corn stover. Several testing methods, including compression, tension, and bend have been investigated to increase our understanding of the biomechanical behavior of cellulosic feedstocks. Biomechanical data from these tests can provide required input to numerical models and help advance harvesting, handling, and processing techniques. In addition, integrating the models with the complete data set from this study can identify potential tools for manipulating the biomechanical properties of plant varieties in such a manner as to optimize their physical characteristics to produce higher value biomass and more energy efficient harvesting practices.

Index Entries: Modulus of elasticity; biomechanics; wheat straw; corn stover; feedstock development.

\section{Introduction}

The vision for a viable bioenergy and bioproducts industry in the U.S. by 2030 estimates that one billion dry tons of sustainable lignocellulosic feedstock will be needed annually (1). Meeting this goal will require a wide variety of feedstock streams as inputs to biorefineries and power plants. Improved harvesting, processing, and bulk handling systems that are capable of separating the more valuable components and densifying the material for transportation and 
processing will need to be developed. Successfully designing and developing these systems requires a fundamental knowledge of the feedstock biomechanical properties and characteristics.

The importance of biomechanical data has long been recognized $(2,3)$. However, the ability to characterize biomass physical properties in a manner that allows estimation of the energy consumption and power requirements of engineered feedstock systems has not been effectively addressed. In fact, the current biomechanical property data is generally limited to one or two varieties and does not attempt to apply the results to broad scale harvesting, processing, and bulk handling systems. In addition, inter-variety comparisons have not been widely investigated to determine the potential sources of mechanical variations. These relationships are needed to develop predictive models that can potentially improve the effectiveness and efficiencies of these systems. Furthermore, inter-variety comparisons can help connect the mechanical behavior of specific plant components to particular loading configurations, providing a path forward for genetically manipulating the varieties in order to optimize their macroscopic and microscopic characteristics.

Addressing the goal of processing one billion dry tons of biomass annually requires focusing the research, at least initially, on the most available, sustainable, and cost effective feedstocks. Agricultural crop residues have been identified as the most likely high-volume lignocellulosic feedstocks available with stover and straw being the feedstocks of choice (1). It is the aim of this study to determine the biomechanical properties of wheat and barley straw and corn stover for the purpose of characterizing differences between varieties and their constitutive components. The long-term goal is to provide significant insight into the macro-scale harvesting, handling, and processing operations and the micro-scale plant genetics and fracture behavior (4). 
Determining the biomechanical properties of wheat, barley and corn is challenging for several reasons. First, biological materials by their very nature are complex composite structures whose components are intimately connected. Unlike engineered composite materials, their interconnected behavior makes it difficult to attribute particular mechanical characteristics to any one component. As a result, only bulk material properties can be easily measured, with additional micro-scale analysis and numerical models needed to discern the attributes of the segregated components. Second, the small size of biological materials makes the specimens difficult to handle with standard mechanical test equipment. Likewise, their relatively soft tissue structure and unique anatomical arrangement compared to traditionally engineered materials increases the need for highly sensitive and delicate instruments. Finally, the variability of biological materials requires the testing of several specimens in order to statistically characterize untested parameters such as harvest location, soil composition, stages of maturity, and other variables dictated by nature and not controlled in engineering environments. Thus, results from mechanically testing biological materials have an element of error that is not readily quantifiable.

The testing and measuring of mechanical properties may be considered to be a macroscale operation. Standard testing procedures used on engineered composite structures can be applied to biological structures to test their performance and determine their material properties under laboratory applied loads. These loads are within the ranges typically seen in industrial machinery that harvest or process biological materials and include chopping, grinding, chipping, and billeting $(3,5)$. However, because of the complexity of biological structures, unique methods must be developed and used to provide sensitive and reliable data within the range of applied loads (6). Mechanical properties determined through laboratory compression, tension, and bend tests can be used as required input to numerical models capable of predicting parameters that 
affect energy consumption, power requirements, and efficiencies of engineered feedstock processing systems $(7,8,9)$. These models will ultimately help optimize machinery design and increase the potential for lowering harvesting, handling, and processing costs.

The physical and mechanical properties of the feedstock are related to the environmental conditions and genetic makeup of the biomass, leading to an additional micro-scale investigation of the biological material (10). Data associated with the anatomical structure of the plant material is helpful in interpreting the mechanical property results and determining modes of failure. Thus, it is useful to record and synchronize the visual aspects of the experimental events with load data to determine micro-scale failure patterns associated with the type of material tested (11). Pre-test and post-test observations are also necessary to identify failure mechanisms related to differences in the structure of individual plant components (i.e., vascular bundles, sclerenchyma, parenchyma, etc.) $(12,13,14,15)$.

This paper presents an approach in which mature (harvested) biomass was collected and tested to determine the modulus of elasticity and ultimate strength for internodal stems of two varieties each of wheat and barley, and four cultivars of corn. A miniature load frame used for Environmental Scanning Electron Microscope (ESEM) was adapted to work with barley and wheat straw, while an Instron load frame was adapted for work with corn (11). The main objective was to develop a database for each variety and determine whether individual varieties could be identified and separated from one another based on differences in biomechanical properties. This database will be used to develop a conceptual use model for testing biomass materials to estimate biomass performance in harvesting, handling, and processing systems. It is recognized that environmental conditions (i.e., temperature, humidity), stages of maturation, matrix composition, and cell matrix configuration are important test parameters to consider 
$(16,17,18,19,20,21,22)$. For purposes of simplicity, this study primarily focuses on matrix composition and cell configuration in mature plant biomass for the determination of biomechanical properties.

\section{Materials and Methods}

Feedstock

Two varieties each of wheat and barley straw, and four cultivars of corn stover were selected for use in this study. The growth site, and collection and testing dates for each variety are shown in Table 1. Variety selection was based on straw and stover physical characteristics, primarily those that distinguished one from another.

Table 1. Plant (variety) information used in the biomechanical tests.

\begin{tabular}{cccc}
\hline Variety & Growth Site & Collection Date (mm/yyyy) & Testing Date (mm/yyy) \\
\hline Amidon (wheat) & Aberdeen, Idaho & $08 / 2002$ & $03 / 2003-03 / 2004$ \\
Westbred 936 (wheat) & Aberdeen, Idaho & $08 / 2002$ & $03 / 2003-03 / 2004$ \\
Bowman (barley) & Aberdeen, Idaho & $08 / 2002$ & $03 / 2003-03 / 2004$ \\
Fragile Stem 1 (barley) & Aberdeen, Idaho & $08 / 2002$ & $03 / 2003-03 / 2004$ \\
\hline Bearclaw 7998 (corn) & Ames, Iowa & $10 / 2002$ & $04 / 2004$ \\
Dekalb 611 (corn) & Ames, Iowa & $10 / 2002$ & $04 / 2004$ \\
Garst 8550 (corn) & Ames, Iowa & $10 / 2002$ & $04 / 2004$ \\
Iowa 550473 (corn) & Ames, Iowa & $10 / 2002$ & $04 / 2004$ \\
\hline
\end{tabular}

Westbred 936 is a semi dwarf variety of hard red spring wheat with a strong, stiff straw giving it lodging resistance (a plants tendency not to tip-over from external forces). In 2002, it was the top wheat variety grown in southeastern Idaho, whose chemical composition (lignin, hemicellulose, and cellulose content) has also been extensively analyzed at the INEEL (23).

Amidon, a standard height hard red spring wheat variety, was chosen because of its moderate resistance to lodging, intermediate level of stem solidness, and medium straw strength. Its semi-solid stem distinguishes its cross-sectional composition from that of the more typical hollow-stemmed Westbred 936. 
The varieties of wildtype Bowman and its fragile stem mutant, $f s t$ 1.d (24), were chosen because of their closely tied genetic makeup. The leaves and stems of the fragile stem mutant plants easily break when physically bent. They are extraordinary fragile even after maturity. In homozygous lines, straw collapse and/or lodging occur more frequently compared to the wildtype Bowman. In contrast, Bowman has good tolerance to late-season lodging and postmaturity straw breakage. It is the parental line used in the introgression of $f_{s t}$ 1.d.

Each cultivar of corn was chosen based on field standability, apparent strength when handled, and, for logistical purposes, the internodal stalk length. The first variety, Bearclaw 7998, is a popcorn cultivar originating in Ohio. It is smaller in stature compared to the other cultivars and has an apparent weaker stock than most. The next two varieties, Dekalb 611 and Garst 8550, are both commercial cultivars managed in fields at Iowa State University. Dekalb 611 was chosen for its poor standability and long, straight internodal regions. Garst 8550, on the other hand, was chosen for its high standability and long internodal regions. Finally, Iowa 550473 is a parental stiff stalk cultivar originating from Ontario, Canada. It was chosen because of its stiff stalk genetic background and noticeably larger stalk geometry.

The various samples tested in this study were collected during the 2002 cropping season and put into dry boxed storage until the time of use. The moisture content, though an important physical parameter of bio-based materials (5), was not a variable in this study in order to limit the parameters tested and focus on the cellulosic and lignin components of the material.

\section{Testing Methods}

Several testing methods, including compression, tension, and bend were used to determine the mechanical characteristics of agricultural residues. These methods were performed with load frames sized to accommodate both wheat and barley stems and corn stover. 
Video imaging techniques were used to follow and confirm load test measurements. Pre- and post-mortem microscopic analyses helped to identify changes in structural components based on the type of test conducted. Each test provided a range of mechanical data from different parts of the plant and from different varieties of wheat, barley, and corn.

The test results provided two useful quantities, the modulus of elasticity and the ultimate strength of the material. Seven samples from each variety were tested in order to statistically represent their material properties. The mean and standard deviation of these quantities were used to establish similarities and differences between varieties according to their mechanical behavior. Only test data that was complete at the time of this paper is reported. Therefore, this paper contains results from compression, tension, and bend tests of wheat and barley specimens and compression tests of corn specimens.

\section{Specimen Selection}

Test specimens from specific internodal regions were obtained from different plants and different varieties. The testing region chosen for the wheat and barley varieties was the second internode down from the top of the plant, or grain head, as seen in Figure 1a. Other investigators have used this region, which provides opportunities to compare test results $(5,25)$. Similarly, the corn samples were cut from internodal regions consistent across the four varieties chosen for this study. These regions, however, were referenced from the cob location and not the top of the plant, since the internodes at the cob locations are significantly deformed during growth. Thus, all corn samples were cut from the internodal regions just above and just below the cob locations according to Figure $1 \mathrm{~b}$. 


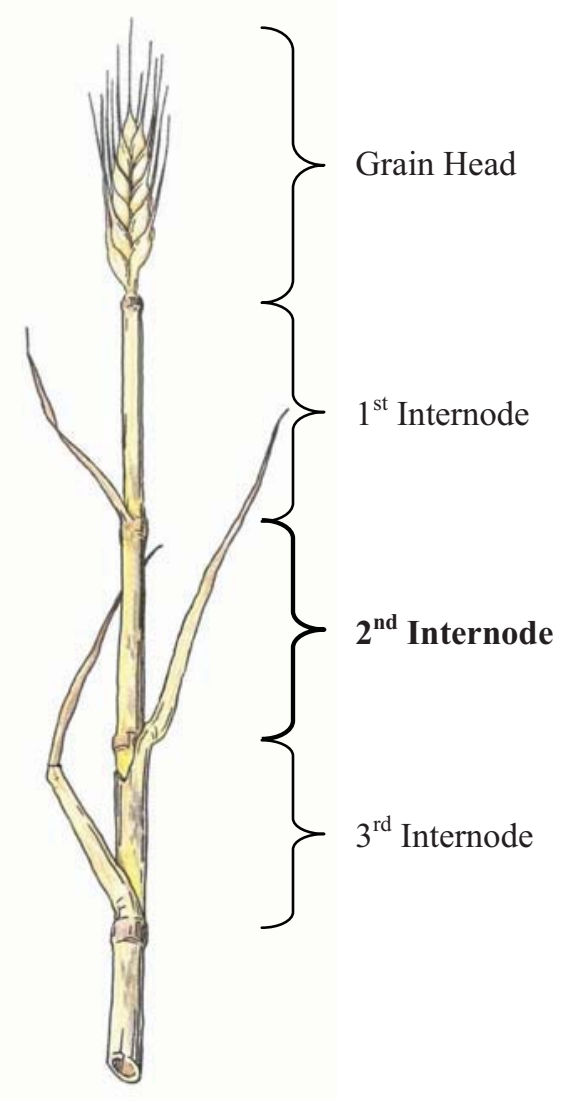

a)

Figure 1. Artist rendering of a wheat or barley stem (a) and corn stock (b). The internodal test regions used in this study are identified in bold.

\section{$\underline{\text { Bend and Tension Tests }}$}

Wheat and barley specimens for the bend and axial tension tests were cut to $76 \mathrm{~mm}$ lengths from the center of the second internodal region providing one specimen per internode per plant. Each specimen was set in the cradle of the bend apparatus with its major axis aligned perpendicular to the applied load. Data was logged at a rate of two points per second with a load travel rate of $2.4 \mathrm{~mm} / \mathrm{min}$. The data included the applied transverse load, the absolute displacement of the load point, and the magnified stem images corresponding to each data point. The image data was used to record surface features, structural failures, and to capture the deflection of the stem needed to calculate the bending modulus for each tested specimen. 
Tension test specimens were prepared with special end grips due to the delicate nature of cereal stems and the waxy coating on the surface. The grips consisted of inner pins that fill the ends of the hollow stems providing structural support as the jaws were tightened. On the outside of the stem, a self-adhesive heat shrink-wrap was applied to protect the surface of the stem from damage due to direct contact with the metal jaws. Separate collars made from the same heat shrink-wrap were fixed to the stem 1-inch apart and provided attachment points for the knifeedges of the extensometer, which was used to accurately measure the strain resulting from the tension loading. Each specimen was clamped within the jaws of the load frame and pulled at a uniform rate of $5 \mathrm{~mm} / \mathrm{min}$. Data was logged at a rate of two points per second and included the tension load and the jaw and extensometer displacements. These data were used to create stressstrain curves from which the slope of the linear portion of the curve was recorded as Young's modulus. A picture showing the tension test setup is shown in Figure 2.

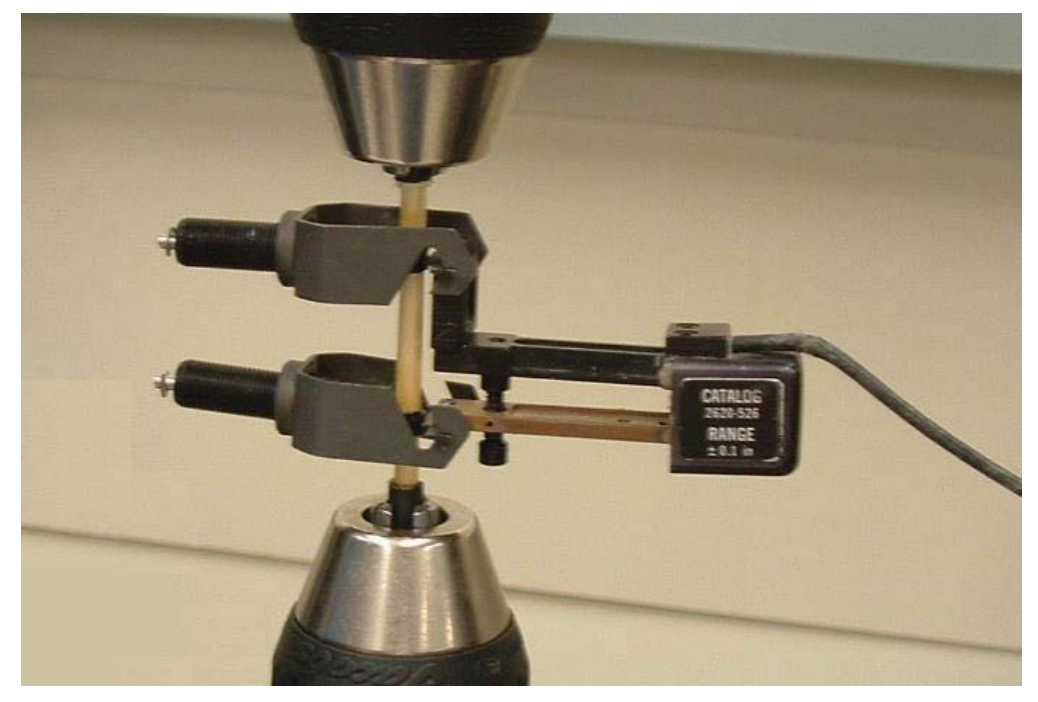

Figure 2. Tension test setup for wheat/barley specimens. The picture shows the load frame jaws, the end grips, the heat shrink collars, and the extensometer.

After testing, both the bend and tension specimens were sectioned through the gage region and a stereo-zoom microscope was used to measure total cross-sectional area, individual 
component areas, major and minor stem diameters, and wall thickness. These geometrical measurements were directly used in the area moment of inertia calculation needed for the bending modulus and in the stress and strain calculations needed for Young's modulus.

\section{$\underline{\text { Compression Tests }}$}

Wheat and barley specimens for the compression tests were taken from the same internodal regions described for the bend and tension tests. Each specimen was cut to an equal height to length ratio (1:1) to increase its resistance to buckling. Two samples each were cut from the top and bottom of the internodal region allowing the potential for differences across internodal stem lengths to be examined. Once cut, the specimens were placed vertically in the load frame and compressed at a rate of $2.4 \mathrm{~mm} / \mathrm{min}$. Image data was logged at a rate of two frames per second to record surface features as the specimens failed due to buckling. Prior to each test, end cross-section images were collected with a stereo-zoom microscope to obtain geometrical data required for the calculation of stress-strain curves. The slope of the linear portion of these curves was used to determine the compressive modulus of the specimens.

The compression specimens for corn were prepared in a similar manner as those for wheat and barley, keeping the same length to diameter ratio of 1:1. Unlike the wheat and barley specimens, however, the set of seven corn specimens for each variety were cut from the same internodal region, one internode above and below the cob location. This sampling technique provided the means to test variations in the same plant across different stover locations. The test specimens were compressed at a rate of $5 \mathrm{~mm} / \mathrm{min}$ with load, displacement, and image data collected over the course of the test. These data, along with each specimen's geometrical measurements made prior to testing, were used to construct stress-strain curves and determine the compression modulus from the linear portion of these curves. 


\section{Results}

Representative stained cross-sectional images of the wheat and barley stems, and corn stover are shown in Figures 3 and 4. These images show details of the sclerenchyma (outer rind or epidermis), parenchyma (inner cells or matrix of the structure), and vascular bundles. These images provide the cross-sectional area data necessary to calculate the stress in the stem during testing and to detail the major components of the specimens, which are responsible for the mechanical behavior of each variety.

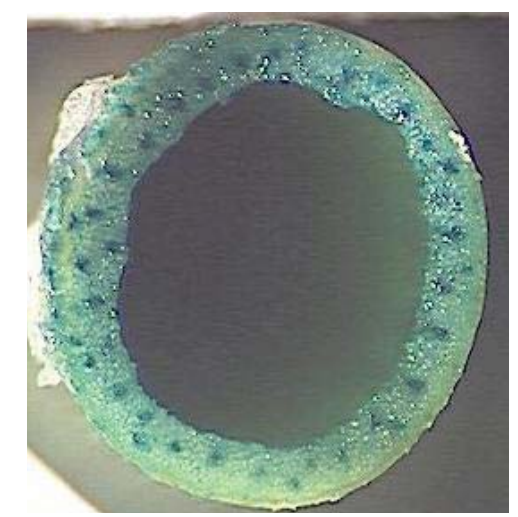

a)

Figure 3. Cross-sectional images of Westbred wheat (a) and Fragile Stem 1 barley (b) varieties, stained with alcian blue dye (26).

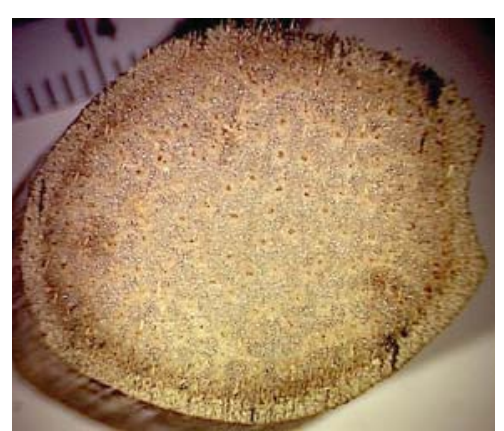

a)

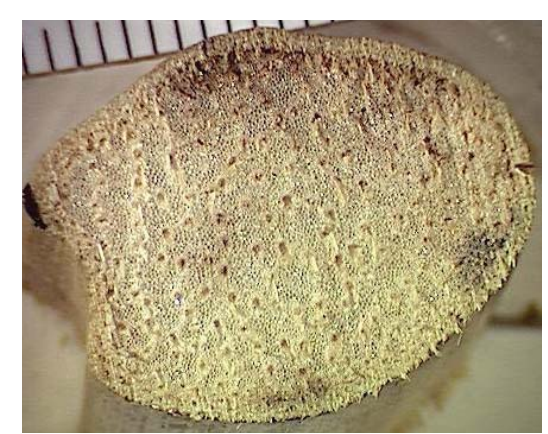

b)

Figure 4. Cross-sectional images of Iowa 550473 (a) and Dekalb 611 (b) corn varieties.

Table 2 contains details of the chemical composition of each variety tested. The percentages of the four major components of the plant structures (i.e. cellulose, hemicelluloses, lignin, and ash) are reported. 
Table 2. Polymer and ash compositions of the wheat, barley, and corn varieties tested.

\begin{tabular}{cccccc}
\hline Variety & \% Cellulose & $\begin{array}{c}\text { \% } \\
\text { Hemicellulose }\end{array}$ & $\begin{array}{c}\text { \% Lignin \& } \\
\text { Extractives }\end{array}$ & \% Ash & \% Unidentified \\
\hline Amidon (wheat) & 38.2 & 18.7 & 20.0 & 5.1 & 17.9 \\
Westbred 936 (wheat) & 39.9 & 18.6 & 21.4 & 6.0 & 14.1 \\
Bowman (barley) & 35.3 & 16.2 & 18.2 & 7.1 & 23.2 \\
Fragile Stem 1 (barley) & 11.1 & 22.1 & 16.7 & 18.3 & 31.8 \\
\hline Bearclaw 7998 (corn) & 32.2 & 18.1 & 17.7 & 5.8 & 26.1 \\
Dekalb 611 (corn) & 35.2 & 17.6 & 17.7 & 3.6 & 26.0 \\
Garst 8550 (corn) & 33.9 & 13.0 & 19.1 & 3.2 & 30.7 \\
Iowa 550473 (corn) & 33.3 & 17.5 & 19.5 & 4.3 & 25.4 \\
\hline
\end{tabular}

Compositions calculated using standard Quantitative Saccharification wet chemistry method (27).

The modulus of elasticity results from the 3-and 4-point bend, axial compression, and axial tension tests are shown in Table 3. In all cases, applied load, displacement, and total crosssectional area measurements were used to calculate the respective modulus. Modulus values for compression and tension were calculated from the slope of the linear portion of the stress-strain curves. For the 3- and 4-point bend tests, moduli were calculated using equations derived from standard beam theory for specimens with circular cross-sections (28). The equations for 3-point and 4-point bends, respectively, are:

$$
\begin{gathered}
E=\frac{P L^{3}}{48 \delta I_{b}} \\
E=\frac{P a}{48 \delta I_{b}}\left[3 L^{2}-4 a^{2}\right]
\end{gathered}
$$

where $P$ is the applied load, $L$ is the distance between the support points, $\delta$ is the deflection of the stem, and $a$ is the distance between the support and load points. The area moment of inertia in bending about the major axis, $I_{b}$, is given by (18),

$$
I_{b}=\frac{\pi}{4}\left[a b^{3}-(a-t)(b-t)^{3}\right]
$$

where $a$ is the semi-major axis, $b$ is the semi-minor axis, and $t$ is the mean wall thickness of the stem cross-section. 
Table 3. Mean modulus of elasticity values for wheat and barley stems, and corn stover.

\begin{tabular}{ccccc}
\hline \multirow{2}{*}{ Variety } & 3-Pt Bend & \multicolumn{2}{c}{ 4-Pt Bend } & Compression \\
\cline { 2 - 5 } & \multicolumn{4}{c}{ Modulus (GPa) } \\
\hline Amidon (wheat) & $2.2 \pm 0.23 \mathrm{a}^{\dagger}$ & $2.2 \pm 0.18 \mathrm{a}$ & $0.60 \pm 0.11 \mathrm{a}$ & $7.3 \pm 0.92 \mathrm{a}$ \\
Westbred 936 (wheat) & $1.1 \pm 0.076 \mathrm{~b}$ & $1.3 \pm 0.020 \mathrm{~b}$ & $0.90 \pm 0.47 \mathrm{a}$ & $4.9 \pm 0.74 \mathrm{~b}$ \\
Bowman (barley) & $1.3 \pm 0.087 \mathrm{~b}$ & $1.4 \pm 0.058 \mathrm{~b}$ & $0.42 \pm 0.08 \mathrm{~b}$ & $3.4 \pm 0.57 \mathrm{c}$ \\
Fragile Stem 1 (barley) & $1.1 \pm 0.063 \mathrm{~b}$ & $1.3 \pm 0.035 \mathrm{~b}$ & $0.97 \pm 0.38 \mathrm{a}$ & $3.5 \pm 0.37 \mathrm{c}$ \\
\hline Bearclaw 7998 (corn) & - & - & $0.26 \pm 0.06 \mathrm{a}$ & - \\
Dekalb 611 (corn) & - & - & $0.38 \pm 0.04 \mathrm{~b}$ & - \\
Garst 8550 (corn) & - & - & $0.47 \pm 0.12 \mathrm{c}$ & - \\
Iowa 550473 (corn) & - & - & $0.40 \pm 0.10 \mathrm{~b}$ & - \\
\hline
\end{tabular}

${ }^{\dagger}$ Means followed by the same letter in a column do not differ significantly ( $\left.\mathrm{P}>0.05\right)$ according to the StudentNewman-Keuls pairwise multiple comparison method. Scatter in the data is reported with a standard error.

The structural variations of the varieties tested in this study are presented in Table 4.

These values were optically measured using images from a stereo-zoom microscope and analysis tools from Image Pro Plus software. The reported values represent statistical means calculated from the specimens used in each test. Each measured component represents only the major part of the plant's structure that could be readily segregated with the microscope. To illustrate the correlation between columns of data in Table 4, the product of columns A and B is statistically equal to the product of columns $\mathrm{A}, \mathrm{D}$, and $\mathrm{E}$, which is the total fiber cross-sectional area.

Table 4. Structural analysis of the wheat, barley and corn materials identifying the varies components.

\begin{tabular}{cccccc}
\hline Variety & $\begin{array}{c}\text { Stem/Stalk } \\
\text { Cross-sectional } \\
\text { Area }\left(\mathrm{mm}^{2}\right)\end{array}$ & $\begin{array}{c}\text { \% Total Fiber } \\
\text { Area }\end{array}$ & $\begin{array}{c}\text { \% Total Rind } \\
\text { Area }\end{array}$ & $\begin{array}{c}\text { Fiber Density } \\
\text { (\# fibers/total cross- } \\
\text { sectional area) }\end{array}$ & Fiber Area $\left(\mathrm{mm}^{2}\right.$ ) \\
\hline Amidon (wheat) & $4.5 \pm 0.30 \mathrm{a}^{\dagger}$ & $10.5 \pm 0.80 \mathrm{a}$ & $19.8 \pm 1.2 \mathrm{a}$ & $8.9 \pm 0.95 \mathrm{a}$ & $0.012 \pm 0.0010 \mathrm{a}$ \\
Westbred 936 (wheat) & $4.9 \pm 0.25 \mathrm{a}$ & $7.2 \pm 0.77 \mathrm{~b}$ & $15.1 \pm 0.98 \mathrm{~b}$ & $7.0 \pm 0.57 \mathrm{~b}$ & $0.011 \pm 0.0011 \mathrm{ac}$ \\
Bowman (barley) & $2.5 \pm 0.086 \mathrm{~b}$ & $8.6 \pm 0.49 \mathrm{~b}$ & $15.8 \pm 1.5 \mathrm{~b}$ & $15.9 \pm 1.4 \mathrm{c}$ & $0.006 \pm 0.0005 \mathrm{~b}$ \\
Fragile Stem 1 (barley) & $2.9 \pm 0.073 \mathrm{c}$ & $8.1 \pm 0.43 \mathrm{~b}$ & $15.5 \pm 0.93 \mathrm{~b}$ & $9.5 \pm 0.39 \mathrm{a}$ & $0.009 \pm 0.0006 \mathrm{c}$ \\
\hline Bearclaw 7998 (corn) & $180.6 \pm 3.4 \mathrm{a}$ & - & $22.6 \pm 0.45 \mathrm{a}$ & - & - \\
Dekalb 611 (corn) & $205.2 \pm 1.3 \mathrm{~b}$ & - & $20.1 \pm 0.98 \mathrm{a}$ & - & - \\
Garst 8550 (corn) & $184.6 \pm 2.1 \mathrm{a}$ & - & $17.5 \pm 0.88 \mathrm{~b}$ & - & - \\
\multicolumn{7}{c}{ Iowa 550473 (corn) } & $368.2 \pm 13.1 \mathrm{c}$ & - & $21.4 \pm 0.85 \mathrm{a}$ & - & - \\
\hline
\end{tabular}




\section{Discussion}

The modulus of elasticity data for the two varieties of wheat and barley and four cultivars of corn indicated significant differences in their mechanical behavior (Table 3). These differences can be attributed to the individual structure and composition of the stems as shown in Figures 3 and 4 and the measured results of the testing. The structural differences (Table 4) can partially be attributed to the size of the cell structures and vascular bundles; and in the case of corn, the thickness of the rind region, which are common across the respective varieties. These structural differences and how they relate to the modulus values illustrated the anisotropic behavior of the material, which was consistent with composite structures.

The compositional differences, shown in Table 2, provide another degree of comparison between varieties. One example of these differences is shown in Figure 3 where the alcian blue staining technique, which highlights the polysaccharides or cellulose content (26), is applied to a Westbred and Fragile Stem specimen capturing the compositional differences reported in Table 2. These compositional differences directly apply to the biomechanical characteristics of a plant through the expression of the individual components. For example, lignin provides structural strength and rigidity to the plant while cellulose and hemicellulose hold the plant together and give it the necessary substance to perform biological operations.

With both structural and compositional data available, specific mechanical characteristics among different plant varieties can be attributed to specific plant structures. An ideal example is a comparison between the wildtype Bowman and Fragile Stem 1 barleys. These two varieties are genetically identical with the exception of one gene (24). This genetic difference affects many parameters one of which was the cellulose composition in the plant (Table 2). Because of their close relationship and known genetic differences, a comparison of their mechanical properties 
can trace differences back to changes in the their respective ultastructures, helping to identify specific stem components that contribute to a particular mechanical behavior.

The basic structure of wildtype Bowman and Fragile Stem 1 barleys is the same, quantified by the individual and combined percentages of stem cross-sectional areas occupied by the rind and the vascular bundles. However, the vascular bundle density per unit area (the number of fibers normalized by the cross-sectional area) between the two varieties was different (Table 4). Taking an engineered composite structure approach, it was theorized that the rind and vascular bundles make up the primary structural support of the stem, while the remaining cell structures, commonly known as the parenchymatic tissue, make up the matrix fill holding the structural components together. Since the fiber and matrix components of engineered composites are made from different materials, they each have different material properties causing the structure as a whole to behave differently depending on the applied load. Similarly, the Bowman and Fragile Stem varieties of barley are seen to behave the same under bending and tension loads but differently under compression based on the measured bulk modulus values.

Differences in the modulus values for wildtype Bowman and Fragile Stem 1 is in part due to the difference in fiber density between the varieties (see Table 4). Under a compressive load, this difference can cause the apparent modulus of the Bowman variety to be lower than the Fragile Stem because of a tendency for many small vascular bundles to bend more readily than a few large bundles. In other words, consider the apparent modulus of many thin columns, separated from each other by a distance more than their diameter, versus one thick column with the same total cross-sectional area under the same compressive load. It is accepted that the group of thin columns would buckle or deflect more easily than would the thicker column (28). Thus, the modulus, being highly sensitive to deflection, would appear smaller for the bundle of 
thin columns compared to the single thick column. This effect was illustrated by the different modulus values of the Bowman and Fragile Stem 1 varieties.

The coupled relationship between compression and tension found in either the 3- or 4point bend tests adds a new level of difficulty when making comparisons between varieties. The data, however, seems to support the notion that tension is more dominant than compression when determining the composite moduli under bending loads. This is evident by similar trends in tension and opposite trends in compression for the Bowman and Fragile Stem 1 varieties.

Similarly, a comparison of the modulus values between the two wheat varieties showed a comparable relationship between the percentage of cross-sectional area occupied by the vascular bundles and rind and the total number of vascular bundles present in a stem. This trend showed that the higher modulus values in bending and tension followed the stem with the largest percentage of vascular bundle, and rind cross-sectional area (Amidon), while the stem with fewer vascular bundles (Westbred) had the higher modulus value in compression.

Comparing modulus values across wheat and barley varieties, however, does not exhibit the same trends seen with inter-wheat or inter-barley comparisons. Instead, identifying the differences in the modulus values across wheat and barley varieties required additional information provided by the component compositions (Table 2). For example, using an engineered composite parallel, the fiber and composite material for the wheat and barley varieties was made from different substances making their bulk behavior dependent on both the type of material in each component as well as the physical structure of each component.

The corn data presented in Figure 4 and Tables 2-4 show significant differences between the cultivars tested. Similar to the trends seen in wheat and barley, the corn data identifies structural and compositional components that contribute to the bulk mechanical behavior of each 
cultivar. Future tension and bend tests will be conducted to verify that the approach used to distinguish varieties of wheat and barley can also be used to distinguish different cultivars of corn. Ultimately, the work done with wheat, barley, and corn, will help support the application of the developed approach to other types and varieties of feedstocks.

\section{Conclusions}

The main objective of this work was to investigate the possibility of distinguishing wheat, barley, and corn (and their varieties) from one another based upon their biomechanical properties. This was accomplished with a high degree of certainty by using a suite of tests that included compression, tension, and bend. The results have increased our understanding of the biomechanical behavior of cellulosic feedstocks as they relate to harvest and post-harvest handling practices and the molecular biology of the plants.

The calculations for the modulus of elasticity and ultimate strength required measuring the physical parameters of the stems (i.e., cross sectional area, min/max diameters). Analysis based just on the physical parameters indicated that it was beneficial to measure other features such as the percentage of occupancy of the rind and vascular bundles. Furthermore, the chemical analyses of the plant material helped provide a more complete characterization of the stems. These data aid in the interpretation of the meaning of the biomechanical measurements, as in the case of the barley varieties during the compression and tension tests.

The ability to track significant differences between the varieties and their individual structural and compositional components provides a path forward for tailoring harvesting, handling, and processing operations. Computer models can be developed for parametric studies on specific structural and compositional components in order to optimize their effect on these 
operations. These models can help determine which biomechanical properties affect the energy efficiency relationships associated with harvest and post-harvest handling practices.

The integration of the models with the complete data set from this study also identified the potential tools for manipulating biomechanical properties of the plant varieties. Since these characteristics are inherent to the biomass, genetic manipulation techniques may be applied to design or control the biomechanical properties in such a manner as to optimize their physical characteristics to produce higher value biomass and provide more energy efficient harvesting practices.

\section{Acknowledgments}

We thank the University of Idaho Aberdeen Research and Extension Center and the North Central Regional Plant Introduction Station in Ames, Iowa for their assistance in obtaining the necessary wheat and barley, and corn samples, respectively. Drs. Larry Robertson (University of Idaho), Andris Kleinhofs (University of Washington), Mark Millard and Wayne King (Iowa State University), and Linda Pollak (USDA-ARS, GEM) played a large role in identifying the varieties of wheat, barley, and corn used in this study. We would also like to acknowledge the assistance of Jeffery A. Lacey (Senior Engineer/Scientist) and Tracy P. Houghton (Senior Engineer/Scientist) at the INEEL for the chemical analyses and their assistance in many areas of this research. This work is supported by the US Department of Energy, Assistant Secretary for Energy Efficiency and Renewable Energy (EE) under DOE Idaho Operations Office Contract DE-AC07-99ID13727.

\section{References}

1. U.S. Department of Energy (2003), Roadmap for Agriculture Biomass Feedstock Supply in the United States, November. 
2. Crook, M.J. and Ennos, A.R. (1996), "Mechanical Differences Between Free-standing and Supported Wheat Plants, Triticum aestivum L.” Ann Bot. 77(3), 197-202.

3. White, N.M. and Ansell, M.P. (1983), "Straw-reinforced polyester composites." Journal of Materials Science. 18, 1549-1556.

4. Gowin, J. (1977), "Methods for determining geometry of cereal stalk cross-section." Presented at the 6th International Conference on Agrophysics - Sep 15-18, Lublin, Poland.

5. Annoussamy, M., Richard, G., Recous, S., and Guerif, J. (2000), "Change in mechanical properties of wheat straw due to decomposition and moisture." Applied Engineering in Agriculture. 16(6), 657-664.

6. Zhou, B.L. (1996), "Some progress in the biomimetic study of composite materials." Materials Chemistry and Physics. 45, 114-119.

7. Hepworth, D.G. and Bruce, D.M. (2000), "A method of calculating the mechanical properties of nanoscopic plant cell wall components from tissue properties." Journal of Materials Science. 35(23), 5861-5865.

8. Mishra, S., Naik, J.B., and Patil, Y.P.. (2000), “The compatibilising effect of maleic anhydride on swelling and mechanical properties of plant-fiber-reinforced novolac composites." Composites Science and Technology. 60(9), 1729-1735.

9. Yano, H. and Nakahara, S. (2004), "Bio-composites produced from plant microfiber bundles with nanometer unit web-like network." Journal of Materials Science. 39, 1635-1638.

10. Bao, G. (2002), "Mechanics of biomolecules." Journal of the Mechanics and Physics of Solids. 50, 2237-2274.

11. Stokes, D.J. and Donald, A.M. (2000), "In situ mechanical testing of dry and hydrated breadcrumb in the environmental scanning electron microscope (ESEM)." Journal of Materials Science. 35, 599-607.

12. Hornsby, P.R., Hinrichsen, E., and Tarverdi, K. (1997), "Preparation and properties of polypropylene composites reinforced with wheat and flax straw fibres. Part I. Fibre characterization.” Journal of Materials Science. 32, 443-449.

13. Yamasaki, M. and Sasaki, Y. (2003), "Elastic properties of wood with rectangular cross section under combined static axial force and torque." Journal of Materials Science. 38(3), 603-612.

14. Zhong, R., Taylor, J.J., and Ye, Z.H. (1997), "Disruption of interfascicular fiber differentiation in an Arabidopsis mutant." The Plant Cell. 9, 2159-2170.

15. Zhu, H.X. and Melrose, J.R. (2003), "Time-dependent aspects of the mechanical properties of plant and vegetative tissues.” Journal of Materials Science. 38(11), 2489-2498. 
16. Madsen, B. and Lilholt, H. (2003), "Physical and mechanical properties of unidirectional plant fibre composites \& an evaluation of the influence of porosity." Composites Science and Technology. 63(9), 1265-1272.

17. Mwaikambo, L.Y. and Ansell, M.P. (2001), "The determination of porosity and cellulose content of plant fibers by density methods." Journal of Materials Science Letters. 20, 20952096.

18. O'Dogherty, M.J., Huber, J.A., Dyson, J., and Marshall, C.J. (1995), “A study of the physical and mechanical properties of wheat straw." Journal of Agricultural Engineering Research. $62,133-142$.

19. Ormerod, A.P., Ralfs, J.D., Jackson, R., Milne, J., and Gidley, M.J. (2004), “The influence of tissue porosity on the material properties of model plant tissues." Journal of Materials Science. 39(2), 529-538.

20. Shtilman, M.I., Tsatsakis, A.M., Alegakis, A.K., Voskanyan, P.S., Shashkova, I.M., Rizos, A.K., and Krambovitis, E. (2002), "Structure vs release-rate relationships in polymeric esters of plant growth regulators.” Journal of Materials Science. 37(21), 4677-4682.

21. Stamboulis, A., Baillie, C.A., and Peijs, T. (2001), "Effects of environmental conditions on mechanical and physical properties of flax fibers." Composites Part A: Applied Science and Manufacturing. 32, 1105-1115.

22. Wietholter, N., GraeSner, B., Mierau, M., Willats, W.G.T. Knox, J.P. and Moerschbacher, B.M. (2003), "Isolation and characterization of the homogalacturonan from type II cell walls of the commelinoid monocot wheat using HF-solvolysis." Carbohydrate Research. 338, 423431.

23. Thompson, D.N., Houghton, T.P., Lacey, J.A., Shaw, P.G., and Hess, J.R. (2003), "Preliminary investigation of fungal bioprocessing of wheat straw for production of strawthermoplastic composites." Applied Biochemistry and Biotechnology. 105-108, 423-436.

24. Davis, M.P., Franckowiak, J.D., Konishi, T., and Lundquist, U. (1997), Barley Genetics Newsletter. 26(5), p. 252.

25. Gowin, J. and Haman, J.S. (1984), "Feasibility of using holographic interferometry to determine the mechanical properties of wheat stalks." Transactions of the American Society of Agricultural Engineers. 697-700.

26. Graham, E.T. and Trentham, W.R. (1998), "Staining paraffin extracted, alcohol rinsed and air dried plant tissue with an aqueous mixture of three dyes." Biotechnic \& Histochemistry. 73(4), 178-185.

27. Saeman, J.F., Bubl, J.L., and Harris, E.E. (1945), "Quantitative saccharification of wood and cellulose." Industrial \& Engineering Chemistry Research. 17(1), 35-37.

28. Gere, J.M., and Timoshenko, S.P. (1990), Mechanics of Materials, $3^{\text {rd }}$ ed., PWS Publishing Co., Boston. 